\title{
Vibration risk evaluation in hand-held harvesters for olives
}

\author{
Giuseppe Manetto, Emanuele Cerruto \\ Department DiGeSA, Section of Mechanics and Mechanisation, University of Catania, Catania, Italy
}

\begin{abstract}
This research aims to evaluate the vibration transmitted to the hand-arm system by two electric portable harvesters, different for size and teeth features of the harvesting head. Moreover, being the bars of the two machines telescopic, they were operated at minimum and maximum length. The acceleration was measured, at different times, in two points, $1 \mathrm{~m}$ apart, next to the hand positions. Finally, measurements were carried out both at no load, in standard controlled conditions, and in field, under ordinary working conditions. To smooth the influence of external factors, the machines were operated by the same operator. The results showed that the greater and heavier harvesting head produced significantly higher acceleration at no load $\left(10.7 \mathrm{~m} / \mathrm{s}^{2}\right.$ vs. $\left.5.5 \mathrm{~m} / \mathrm{s}^{2}\right)$, and comparable acceleration at load ( $\left.13.9 \mathrm{vs.} 14.2 \mathrm{~m} / \mathrm{s}^{2}\right)$. On average, the vibration was significantly higher at load (14.0 vs. 8.1 $\mathrm{m} / \mathrm{s}^{2}$ ). The difference between the two bar lengths was not statistically significant: $9.4 \mathrm{~m} / \mathrm{s}^{2}$ when using the minimum length and $9.8 \mathrm{~m} / \mathrm{s}^{2}$ when using the maximum one. Finally, the difference between the two measuring points was affected by the bar length: it was statistically significant when using the bar at its minimum length only. As far as the components are concerned, at no load the highest acceleration was measured along the bar axis for both harvesting heads $\left(9.2 \mathrm{~m} / \mathrm{s}^{2}\right.$ for the greater head and $4.2 \mathrm{~m} / \mathrm{s}^{2}$ for the smaller one). At load all the three components were comparable in the greater head (about $7.8 \mathrm{~m} / \mathrm{s}^{2}$ ) whereas the $\mathrm{x}$ component was predominant in the other one (11.4 vs. $4.8(\mathrm{y})$ and $\left.6.6 \mathrm{~m} / \mathrm{s}^{2}(\mathrm{z})\right)$.
\end{abstract}

Correspondence: Manetto Giuseppe, Dipartimento DiGeSA, Via S. Sofia 100, 95123 Catania, Italy.

Tel.:+39.095.7147515 - Fax: +39.095 .7147600 .

E-mail: gmanetto@unict.it

Key words: safety, vibration exposure, hand-arm system, facilitating machines

Contributions: the authors contributed equally.

Conflict of interests: the authors declare no potential conflict of interests.

(C) Copyright G. Manetto and E. Cerruto, 2013

Licensee PAGEPress, Italy

Journal of Agricultural Engineering 2013; XLIV(s2):e142

doi:10.4081/jae.2013.s2.e142

This article is distributed under the terms of the Creative Commons Attribution Noncommercial License (by-nc 3.0) which permits any noncommercial use, distribution, and reproduction in any medium, provided the original author(s) and source are credited.

\section{Introduction}

Vibration is probably the most important risk connected with the use of portable machines for olive harvesting. Their large utilisation is aimed at reducing the production costs when farm fragmentation, tree structure, irregular tree layout, sloping lands, prevent the mechanical harvesting. In these cases, hand-held vibrating tools are approximately capable of triplicate the productivity of the workers with respect to the manual harvesting (Famiani et al., 2008).

Unfortunately, these tools have been characterised by lack of comfort and high levels of noise and vibration (Iannicelli and Ragni, 1994; Blandini et al., 1997; Deboli et al., 2008; Pascuzzi et al., 2008). Ergonomics and safety aspects are often underestimated by users, mainly interested in productivity. Workers, when operate with handheld power tools, in most of the cases do not perceive acceleration levels as being too high, so increasing the exposure risk (Vergara et al., 2008) and the probability of appearance of the Raynaud syndrome (Chetter et al., 1998).

The factors influencing the biodynamic response of the hand-arm system are complex and numerous, such as frequency, direction and intensity of the vibration, features of the worker (mass, grip force), of the operating tool (handle, mechanical impedance), and of any antivibrating devices.

An increase in the operator's comfort was achieved when machines powered by electric motors were introduced, characterised by lightness, handiness and very effective in reducing the noise level with respect to those powered by two-stroke engines (Biocca et al., 2008). The vibration level remains quite high and its reduction can be achieved after a proper design or an optimal selection of the operating parameters (Monarca et al., 2007; Pascuzzi et al., 2008; Mallick, 2010).

Based on the results of previous works (Cerruto et al., 2010; Cerruto et al., 2011; Cerruto et al., 2012), this research aims to evaluate the vibration transmitted to the hand-arm system by two electric portable harvesters at varying harvesting head size, bar length, and operating conditions (no load and under ordinary working conditions).

\section{Materials and methods}

\section{The machines}

Experimental tests were carried out by using two electric portable harvesters, assembled by a local manufacturer, different for size of the teeth (the small bars that beat branches and olives during the harvest) and size of the harvesting head. Moreover, being the bars of the two machines telescopic, they were operated at minimum (B1) and maximum length (B2).

Both harvesting head ( $\mathrm{H} 1$ and $\mathrm{H} 2$ ) have a plastic-made box to which are connected two arms with opposed oscillations on a plane orthogonal to the motor shaft and inclined of about $20^{\circ}$ with respect to the bar axis (Figure 1). Each arm carries 4 teeth; another tooth, of less length, is connected to the box, and then not oscillating. All the teeth are in 
carbon fibres. The two harvesting heads differ in length of the two arms, in diameter and length of the teeth, and then in total mass. Their main features are reported in Table 1.

The telescopic bar is made from aluminium, with diameters of 28 (minimum) and $35 \mathrm{~mm}$ (maximum), $1 \mathrm{~mm}$ thick, and lengths of 1390 $\mathrm{mm}$ (minimum) and $2180 \mathrm{~mm}$ (maximum). Taking into account handgrip, harvesting head, and a piece of bar (135 mm long) installed after the hand-grip, the total length of the harvesters ranges from 2060 up to $2850 \mathrm{~mm}$. The total mass is $3.070 \mathrm{~kg}$ when using the head $\mathrm{H} 1$ and 2.960 $\mathrm{kg}$ when using $\mathrm{H} 2$.

The motor is powered by an external $12 \mathrm{~V} \mathrm{DC}$ battery. The maximum power is about $900 \mathrm{~W}$ and the rotating speed about $6300 \mathrm{rpm}$, fixed by an electronic card. Its shaft is connected to a box that, with a gear ratio of 10:58, gets the arms with the teeth moving with oscillating frequency of $18 \mathrm{~Hz}$.

\section{The experimental activity}

Experimental trials were carried out by operating the two machines at no load and on olive trees as under ordinary working conditions. To smooth the influence of external factors, they were operated by the same person. Moreover, to ensure the same power conditions, the battery was kept on charge during all the trials.

No load tests were carried out angling the bar according to three directions, so to cover all the possible orientations assumed during the

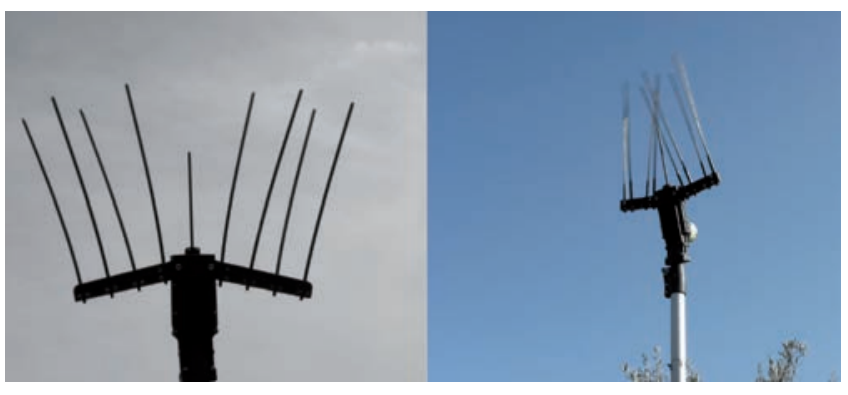

Figure 1. The two harvesting heads: $\mathrm{H1}$ (left) and $\mathrm{H} 2$ (right).

Table 1. Main features of the portable harvesters.

\begin{tabular}{|c|c|c|c|}
\hline & & esting head fe: & ures \\
\hline & H1 & & $\mathrm{H} 2$ \\
\hline No. of teeth & 8 & & 8 \\
\hline Teeth diameter, mm & 6 & & 5 \\
\hline Teeth length, mm & 330 & & 360 \\
\hline Arm length, mm & 155 & & 110 \\
\hline Total width, mm & 390 & & 300 \\
\hline Mass, kg & 1.400 & & 1.290 \\
\hline Bar features & & & \\
\hline Minimum length, $\mathrm{mm}$ & 1390 & Diameter, mm & $35 / 28$ \\
\hline Maximum length, mm & 2180 & Thickness, mm & 1 \\
\hline
\end{tabular}

working activity: vertical $\left(90^{\circ}\right)$, angled at about $45^{\circ}$ and horizontal $\left(0^{\circ}\right)$. Moreover, vibration was measured, at different times, in two points (MP1 and MP2): the first near the hand-grip, the second on the bar, $1 \mathrm{~m}$ apart (Figure 2). Trials on olive trees were conducted in the same manner, but not considering the bar angle as a factor.

Overall, 24 measurement sessions ( 2 harvesting heads $\times 2$ bar lengths $\times 2$ measuring points $\times 3$ angles) at no load and 8 ( 2 harvesting heads $\times 2$ bar lengths $\times 2$ measuring points) at load were carried out, each lasting about 6 minutes.

\section{Signal acquisition and analysis}

Acceleration was measured by using three mono axial accelerometers arranged so to be equivalent to a triaxial accelerometer. The reference coordinate system was fixed in the measuring point MP1 (right hand) according to the UNI EN ISO 5349-1:2004 regulation (ISO, 2004): $\mathrm{x}$-axis perpendicular to the palm surface area, y-axis parallel to the longitudinal axis of the grip, and z-axis directed along the third metacarpus bone of the hand. Considering that the operator, during the harvesting, rotates and changes continually the grip points, the accelerometers were only translated in the measuring point MP2, keeping parallel the reference axes. The accelerometer signals were recorded on the hard disk of a PC by means of a dB4 four-channel acquisition unit and the recording module of the dBFA Suite software (01dB-Metravib, Lyon, France).

Subsequently, they were analysed in laboratory according to the UNI EN ISO 5349-1:2004 regulation by using the post-processing module of the same dBFA Suite software, in the frequency range $5.6-1400 \mathrm{~Hz}$ (third of octave bands from 6.3 up to $1250 \mathrm{~Hz}$ ). In addition, FFT spectra were computed so to detect the main harmonic for each operating condition. To evaluate the variability in time of the vibration level, 5 subsamples of 1 min were extracted from each signal recorded and treated as replicates. On the other hand, being the maximum frequency of interest $1400 \mathrm{~Hz}$, a signal length of about $10 \mathrm{~s}$ is enough for the digital analysis.

Frequency weighted root mean square (RMS) accelerations $a_{h w x}$, $a_{k w y}$, and $a_{h w z}$ were computed via the third octave analysis for each axis, and then it was calculated the global weighted acceleration $a_{h w}$ according to:

$a_{h w}=\sqrt{a_{h w x}^{2}+a_{h w y}^{2}+a_{h w z}^{2}}$

Global values were statistically analysed by means of analysis of variance to detect significant differences related to harvesting head, bar length, measuring point and working conditions (no load or harvesting). Raw data were transformed in order to achieve normal distribution of the residuals and constant variances. However, being the 1minute sub-samples selected without an effective randomisation, mean separation was performed by the more robust non parametric Kruskal-Wallis test.

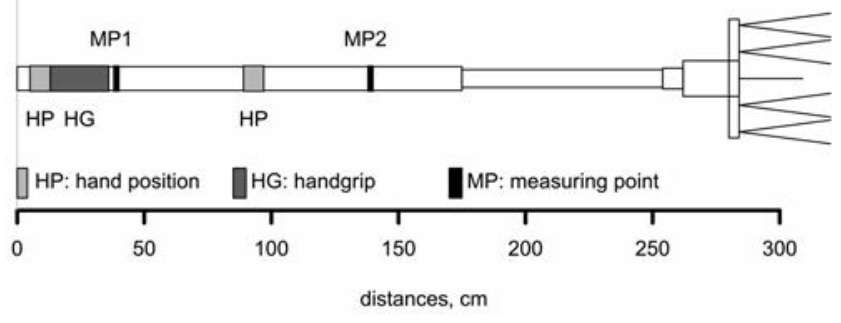

Figure 2. Schematic view of the portable harvesters. 
Finally, the daily vibration exposure values, A(8), were computed according to:

$$
A(8)=\sqrt{\frac{T}{8}} a_{h w}
$$

being $T$ the daily exposure time (h), and compared with the thresholds established by the Italian law 81/08: daily exposure action value of $2.5 \mathrm{~m} / \mathrm{s}^{2}$ and daily exposure limit value of $5.0 \mathrm{~m} / \mathrm{s}^{2}$.

All statistical analyses and graphical representations were carried out by using the open source software $R$ (R Core Team, 2012).

\section{Results and discussion}

\section{Global values}

The comparisons among the levels of the main factors (harvesting head, bar length, operating condition, and measuring point) are summarised in Figure 3, whereas the first order interactions are reported in Table 2.

The box-plots in Figure 3 show a significant difference, confirmed by the analysis of variance ( $p$-level $<0.001$ ), between the two harvesting heads: on average $\mathrm{H} 1$ produces a vibration level much higher than $\mathrm{H} 2$ $\left(11.5 \mathrm{vs} .7 .7 \mathrm{~m} / \mathrm{s}^{2}\right)$. Being the kinematic system of the two heads the same, the difference must be attributed to the different mass and geometry. Moreover, this difference is significantly affected by the working conditions (interaction significant for $p$-level $<0.001$ ): the two harvesting heads produce different vibration only when used at no load
$\left(\mathrm{H} 1=10.7 \mathrm{~m} / \mathrm{s}^{2} ; \mathrm{H} 2=5.5 \mathrm{~m} / \mathrm{s}^{2}\right)$, whereas produce the same vibration during the harvesting $\left(\mathrm{H} 1=13.9 \mathrm{~m} / \mathrm{s}^{2} ; \mathrm{H} 2=14.2 \mathrm{~m} / \mathrm{s}^{2}\right)$. Therefore, during the harvesting, due to the interaction with the tree canopy, the effect of mass and geometry of the harvesting head becomes negligible

Table 2. Global values of the accelerations $\left(\mathrm{m} / \mathrm{s}^{2}\right.$ ) (mean separation by Kruskal-Wallis test for $\boldsymbol{p}$-level $=\mathbf{0 . 0 5}$ ).

\begin{tabular}{lccc} 
Head & Load & No load & Mean \\
H1 & $13.9^{\mathrm{a}}$ & $10.7^{\mathrm{b}}$ & $11.5^{\mathrm{a}}$ \\
H2 & $14.2^{\mathrm{a}}$ & $5.5^{\mathrm{c}}$ & $7.7^{\mathrm{b}}$ \\
\hline Bar length & Load & No load & Mean \\
B1 (minimum) & $14.1^{\mathrm{a}}$ & $7.9^{\mathrm{b}}$ & $9.4^{\mathrm{a}}$ \\
B2 (maximum) & $14.0^{\mathrm{a}}$ & $8.4^{\mathrm{b}}$ & $9.8^{\mathrm{a}}$ \\
\hline Measuring point & Load & No load & Mean \\
MP1 & $11.9^{\mathrm{b}}$ & $7.3^{\mathrm{d}}$ & $8.5^{\mathrm{b}}$ \\
MP2 & $16.2^{\mathrm{a}}$ & $8.9^{\mathrm{c}}$ & $10.7^{\mathrm{a}}$ \\
\hline Mean & $14.0^{\mathrm{a}}$ & $8.1^{\mathrm{b}}$ & $9.6^{\mathrm{a}}$ \\
Measuring point & $\mathrm{B} 1$ & $\mathrm{~B} 2$ & Mean \\
MP1 & $7.9^{\mathrm{b}}$ & $9.0^{\mathrm{ab}}$ & $8.5^{\mathrm{b}}$ \\
MP2 & $10.9^{\mathrm{a}}$ & $10.5^{\mathrm{a}}$ & $10.7^{\mathrm{a}}$ \\
\hline Bar angle & $0^{\circ}$ & $45^{\circ}$ & $90^{\circ}$ \\
& $7.7^{\mathrm{a}}$ & $8.3^{\mathrm{a}}$ & $8.4^{\mathrm{a}}$ \\
\hline
\end{tabular}
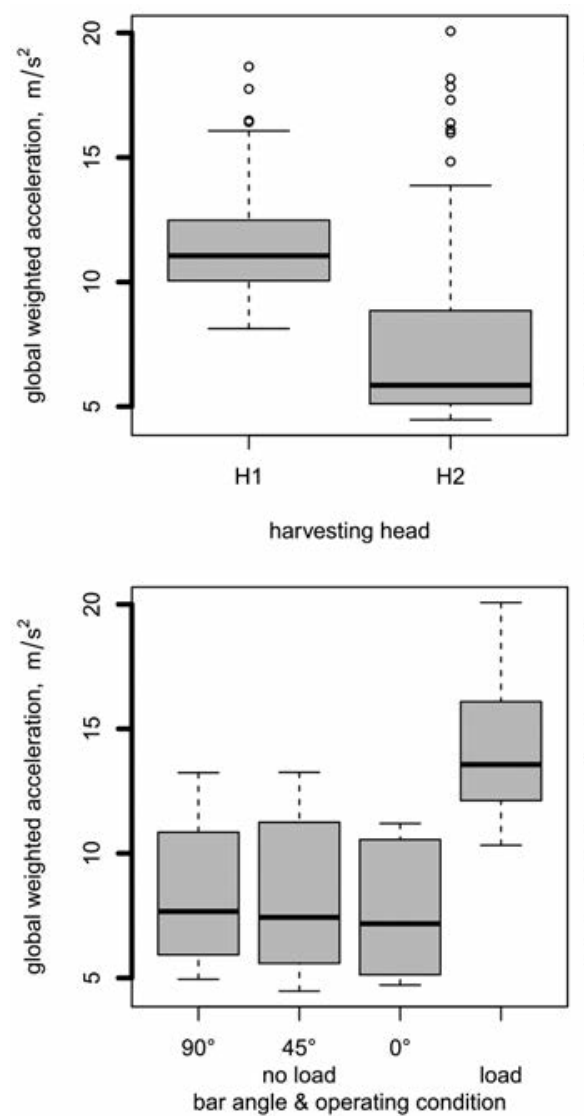
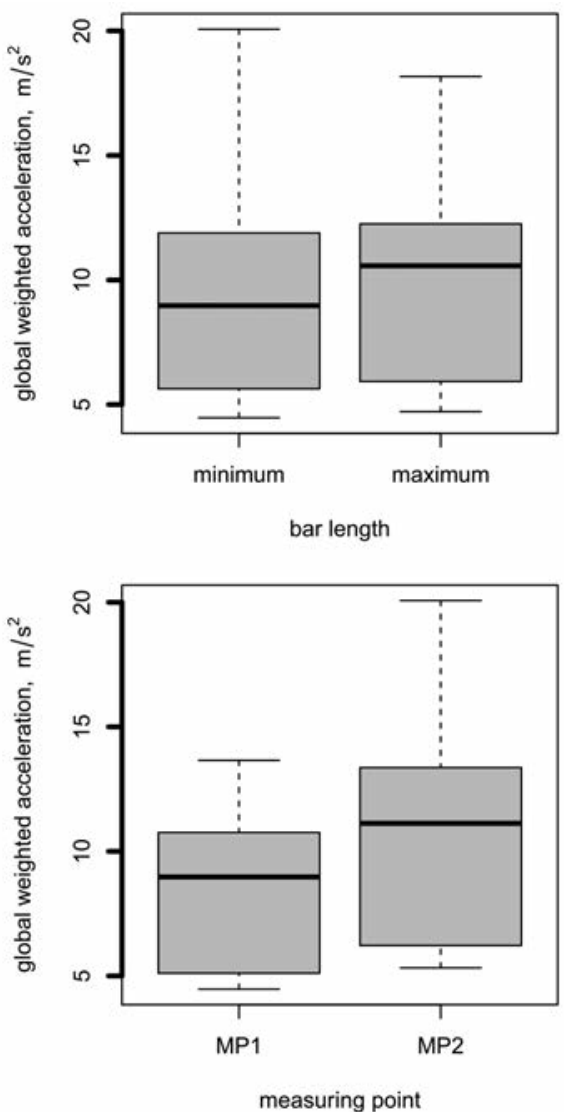

Figure 3. Comparisons among harvesting heads, bar lengths, operating conditions, and measuring points. 
with respect to the mass and geometry of the canopy and the two heads vibrate in the same manner. On average, the vibration is significantly higher at load conditions: $14.0 \mathrm{vs.} 8.1 \mathrm{~m} / \mathrm{s}^{2}$. This result confirms those reported in Cerruto et al. (2012): the vibration increases during the harvesting, due to both canopy effect and force exerted by the operator.

Moreover, the FFT analysis revealed that the working frequency was $18.0 \mathrm{~Hz}$ at no load for both harvesting heads and $15.1 \mathrm{~Hz}$ for $\mathrm{H} 1$ and 16.5 $\mathrm{Hz}$ for $\mathrm{H} 2$ at load. This decrease is due to the interference of the teeth with the canopy, greater in $\mathrm{H} 1$ due to the larger total width of the head ( $390 \mathrm{vs.} 300 \mathrm{~mm})$, that therefore is subjected to a resistant force higher than in H2. In addition, the force resistant is lower in $\mathrm{H} 2$ due to the greater flexibility of its teeth, characterised by greater length ( $360 \mathrm{vs.}$ $330 \mathrm{~mm}$ ) and smaller diameter (5 vs. $6 \mathrm{~mm}$ ).

The difference between the two bar lengths (box-plots in Figure 3 and Table 2) is not statistically significant: the acceleration is on average equal to $9.4 \mathrm{~m} / \mathrm{s}^{2}$ when using the minimum length and $9.8 \mathrm{~m} / \mathrm{s}^{2}$ when using the maximum one. This difference is not affected by the working conditions: the interaction between bar length and working condition is not statistically significant, so the acceleration level is the same for the two bar lengths when the test condition (load or no load) is fixed.

The difference among the three bar angles, evaluated at no load, is not statistically significant (box-plots in Figure 3 and Table 2): each harvesting head produces the same vibration, independently of the bar angle.

Finally, the global acceleration in the measuring point MP2 is greater than that measured in MP1 ( $p$-level $<0.001$ ), but this result is affected by the bar length. In fact, the difference between the two measuring points is statistically significant when using the bar at its minimum length only.

The variability among the 1-minute sub-samples is very small: the coefficient of variation (CV), in fact, ranges from $0.8 \%$ up to $15.6 \%$. As expected, the greatest variability is that measured at load: in these conditions the mean $\mathrm{CV}$ is $8.5 \%$, whereas that measured at no load is $2.8 \%$. This implies, on the one hand, that the operator is exposed to an almost constant level of vibration, and, on the other, that a measuring time of $12 \mathrm{~min}$ is enough for the measurement.

Table 3 reports the exposure times during harvesting activities corresponding to the $A(8)$ daily exposure action value of $2.5 \mathrm{~m} / \mathrm{s}^{2}$ and the daily exposure limit value of $5.0 \mathrm{~m} / \mathrm{s}^{2}$, separately for each bar length and measuring point. The daily exposure limit value ranges from 0.7 up to $1.5 \mathrm{~h}$, clearly incompatible with the standard work-day in agriculture, so the reduction of exposure times through rotating shifts of the operators should be recommended.

\section{Vibration components}

Figure 4 reports the acceleration components at varying harvesting head, working conditions, and measuring point. From it emerges that the main difference between the two harvesting heads at no load is due to the $\mathrm{y}$ component. In fact, whereas $\mathrm{x}$ and $\mathrm{z}$ components are on average comparable (3.4 and $2.8 \mathrm{~m} / \mathrm{s}^{2}$ the x component and 2.2 and $3.7 \mathrm{~m} / \mathrm{s}^{2}$ the $\mathrm{z}$ component for $\mathrm{H} 1$ and $\mathrm{H} 2$ respectively), the y component is $9.2 \mathrm{~m} / \mathrm{s}^{2}$ for $\mathrm{H} 1$ and $4.2 \mathrm{~m} / \mathrm{s}^{2}$ for $\mathrm{H} 2$.

When the working conditions change (from no load to load), the greatest increase in acceleration is observed in the $\mathrm{x}$ component (from 3.4 to $8.3 \mathrm{~m} / \mathrm{s}^{2}$ for $\mathrm{H} 1$ and from 2.8 to $11.4 \mathrm{~m} / \mathrm{s}^{2}$ for $\mathrm{H} 2$ ) and in the $\mathrm{z}$ component (from 3.7 to $7.2 \mathrm{~m} / \mathrm{s}^{2}$ for $\mathrm{H} 1$ and from 2.2 to $6.6 \mathrm{~m} / \mathrm{s}^{2}$ for $\mathrm{H} 2$ ), whereas the y component presents the smallest changes: from 9.2 to 8.0 $\mathrm{m} / \mathrm{s}^{2}$ for $\mathrm{H} 1$ and from 4.2 to $4.8 \mathrm{~m} / \mathrm{s}^{2}$ for $\mathrm{H} 2$. The variations of the $\mathrm{x}$ and $\mathrm{z}$ components from no load to load are explainable by observing that the teeth beat the branches along these two directions. Therefore the branches introduce another source of vibration that produces the increase in the global acceleration level.
Table 3. Exposure times (h) during harvesting corresponding to the $A(8)$ daily exposure action value and daily exposure limit value.

\begin{tabular}{lcccc} 
Bar & \multicolumn{2}{c}{ Bar B1 } & \multicolumn{2}{c}{ Bar B2 } \\
Measuring point & MP1 & MP2 & MP1 & MP2 \\
$a_{h w}, \mathrm{~m} / \mathrm{s}^{2}$ & 11.4 & 16.8 & 12.4 & 15.7 \\
$\mathrm{~A}(8)=2.5 \mathrm{~m} / \mathrm{s}^{2}$ & 0.4 & 0.2 & 0.3 & 0.2 \\
\hline $\mathrm{A}(8)=5.0 \mathrm{~m} / \mathrm{s}^{2}$ & 1.5 & 0.7 & 1.3 & 0.8 \\
\hline
\end{tabular}

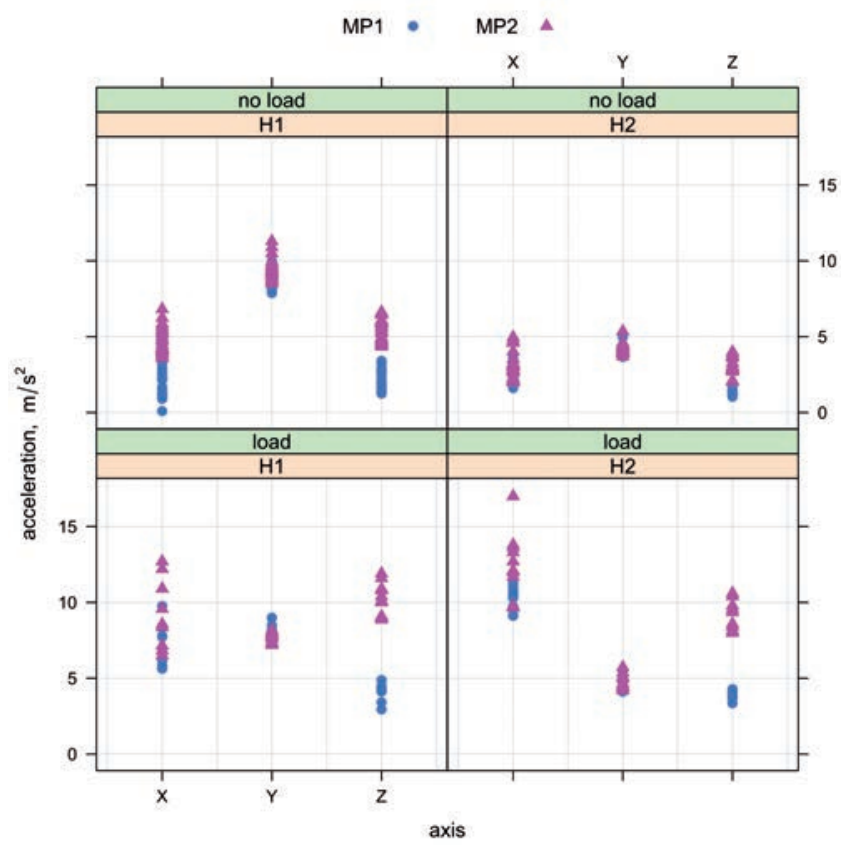

Figure 4. Acceleration components at varying harvesting head, working conditions, and measuring point.

\section{Conclusions}

The use of olive portable harvester if by one side has permitted to triplicate the productivity of the workers with respect to the manual harvesting, by another side has increased the risk for the safety of the operators due to the high acceleration level which are subjected. This is influenced by several aspects, but the main is the kinematic of the machine.

The research carried out has pointed out that:

the branches produce a significant increase in the acceleration level with respect to the no load functioning; furthermore, the mass of the tree canopy nullifies the significant differences in the global acceleration levels between the two heads measured during the no load tests;

- the two harvesters studied, thank their kinematic, produce acceleration levels lower than those measured in other flap-type machines analysed in previous researches (Cerruto et al., 2012) (about 14 vs. $20 \mathrm{~m} / \mathrm{s}^{2}$ ); however, the stress for the workers remain so high that the daily exposure limit value ranges from 0.7 up to $1.5 \mathrm{~h}$, incompatible with the standard work-day; 
- the increase in the bar length with a telescopic system does not evidence significant difference in the global acceleration level between minimum and maximum length during both load and no load running; the variation in length, instead, has effect on the global acceleration measured in correspondence of the hand-grip: at the maximum bar length the global acceleration value increases and becomes statistically equal to that measured in the measuring point on the bar;

- the workers that operate with these machines are exposed to an almost constant level of vibration, as evidenced by the low coefficient of variations among the 1-minute sub-samples of the signal recorded during the tests (on average, 8.5\%).

Finally, taking into account the results obtained, being the exposure time greater than the daily exposure limit, it is necessary to hypothesize rotating shifts among two or three operators during the work-day; on the other hand, to place the nets and to collect the olives from the ground require two operators. Therefore, operators must be informed about health risks and should take safety precautions to reduce continuous vibration exposures over long periods.

\section{References}

Biocca M., Fornaciari L., Vassalini G. 2008. Noise risk evaluation in electrical hand-held picking machines for olive harvesting. Proc. Int. Conf. Agr. Eng. "Agricultural and biosystems engineering for a sustainable world" June 23-25, Hersonissos, Crete, Greece, CDROM.

Blandini G., Cerruto E., Manetto G. 1997. Rumore e vibrazioni prodotti dai pettini pneumatici utilizzati per la raccolta delle olive. Proc. AIIA, September 11-12, Ancona, Italy, 4:229-38.

Cerruto E., Manetto G., Schillaci G. 2010. Vibrations produced by electric shakers for olive harvesting. Proc. Int. Conf. "Work Safety and Risk Prevention in Agro-Food and Forest Systems", September 1618, Ragusa, Italy, CD-ROM.

Cerruto E., Manetto G., Schillaci G. 2011. Vibrations transmitted to the hand-arm system by electric shakers during olive harvesting. Proc. Int. Conf. XXXIV CIOSTA-CIGR V "Efficient and sale production processes in sustainable agriculture and forestry", June 29-July 1, Vienna, Austria, CD-ROM.
Cerruto E., Manetto G., Schillaci G. 2012. Vibration produced by handheld olive electrical harvesters. Journal of Agricultural Engineering 2012, volume XLIII:e12, ISSN 1974-7071, doi:10.4081/jae.2012.e12, $79-85$.

Chetter I.C., Kent P.J., Kester R.C. 1998. The hand arm vibration syndrome: a review. Cardiovasc. Surg. 6:1-9.

Deboli R., Calvo A., Preti C. 2008. The use of a capacitive sensor matrix to determine the grip forces applied to the olive hand held harvesters. Proc. Int. Conf. "Innovation Technology to Empower Safety, Health and Welfare in Agriculture and Agro-food Systems", September 15-17, Ragusa, Italy, CD-ROM.

Famiani F., Giurelli A., Proietti P., Nasini L., Farinelli D., Guelfi P. 2008. Sì alla raccolta agevolata in oliveti tradizionali ed intensivi. L'Informatore Agrario 4:103-7.

Iannicelli V., Ragni L. 1994. Agevolatrici vibranti per la raccolta delle olive. Riv. Ing. Agr. 25:248-56.

IS0, 2004. Mechanical vibration measurement and evaluation of human exposure to hand-transmitted vibration - part 1: general requirements. Norm ISO 5349-1:2004. International Organization for Standardization Publ., Geneva, Switzerland.

Italian Regulation. 2008. Attuazione dell'articolo 1 della legge 3 agosto 2007 , n. 123, in materia di tutela della salute e della sicurezza nei luoghi di lavoro, LD 81/2008. In: Gazzetta Ufficiale no. 101, 30/04/2008, suppl. ordinario n. 108.

Mallick Z. 2010. Optimization of the operating parameters of a grass trimming machine. Appl. Ergonom. 41:260-5.

Monarca D., Cecchini M., Colantoni A. 2007. Study for the reduction of vibration levels on an "Olive electrical harvester". Proc. XXXII CIOSTA-CIGR Sect. V Conf., September 17-19, Nitra, Slovakia, Part II:503-9.

Pascuzzi S., Santoro F., Panaro V.N. 2008. Study of workers' exposures to vibrations produced by portable harvesters. Proc. Int. Conf. "Innovation Technology to Empower Safety, Health and Welfare in Agriculture and Agro-food Systems", September 15-17, Ragusa, Italy, CD-ROM.

R Core Team, 2012. R: A language and environment for statistical computing. R Foundation for Statistical Computing, Vienna, Austria. Available from: http://www.R-project.org/.

Vergara M., Sancho J.-L., Rodríguez P., Pérez-González A. 2008. Handtransmitted vibration in power tools: Accomplishment of standards and users' perception. Int. J. Ind. Ergonom. 38:652-60. 